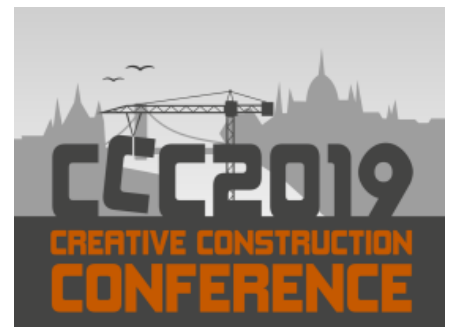

Available online at 2019.creative-construction-conference.com/proceedings/

CCC 2019

Proceedings of the Creative Construction Conference (2019) 125

Edited by: Miroslaw J. Skibniewski \& Miklos Hajdu

https://doi.org/10.3311/CCC2019-125

Creative Construction Conference 2019, CCC 2019, 29 June - 2 July 2019, Budapest, Hungary

\title{
USING AUGMENTED REALITY FOR MASONRY AND CONCRETE EMBED COORDINATION
}

\author{
Darren Olsen $^{\mathrm{a}^{*}}$, Jeffrey Kim ${ }^{\mathrm{a}}$, J. Mark Taylor ${ }^{\mathrm{a}}$ \\ ${ }^{a}$ Auburn Univeristy, Auburn, Alabama, 36839, US
}

\begin{abstract}
Missing or misaligned embeds, sleeves and penetrations for concrete and masonry construction have historically caused disruptions and errors in commercial construction resulting in delays, rework and cost overruns. In order to locate embeds, sleeves and penetrations through the traditional process requires a special set of coordination drawings to be produced called "lift drawings." The "lift drawings" are essentially elevation views of critical wall and foundations elements which show the exact location and alignment for the embeds or penetrations. Producing these "lift drawings" is a time consuming and tedious process that is typically undertaken by the construction management professionals in order to assure that these elements are located properly within the building.

In the age of BIM this process of producing "lift drawings" for embeds, sleeves and penetrations should be coordinated and streamlined using BIM and augmented reality to reduce the work effort and provide greater efficiencies. This paper seeks to discover ways in which BIM combined with augmented reality and traditional surveying hardware can improve the process of embed, sleeve and penetration coordination.
\end{abstract}

(C) 2019 The Authors. Published by Budapest University of Technology and Economics \& Diamond Congress Ltd. Peer-review under responsibility of the scientific committee of the Creative Construction Conference 2019.

Keywords: Augmented Reality, BIM, Coordination, Surveying

\section{Introduction}

Concrete or masonry embedments ("embeds") are used extensively in commercial construction, embeds serve as connection points between dissimilar materials. Oftentimes you see steel embeds used in concrete and masonry construction to allow the connection and attachment of structural steel members to a previously installed concrete or masonry structure. A traditional problem with embeds is that oftentimes they bridge a gap between two separate subcontractor's scope of work, and if they are excluded or omitted those two separate scopes cannot be efficiently integrated together. Since embeds serve as the necessary link between the two separate scopes of work (e.g. concrete and structural steel) that dependence often times leads to a points of contention and lengthy disputes. Contractors have long recognized that embeds can lead to conflict resulting in costly and time consuming rework, and therefore have used a number of different strategies to defuse the problem. Despite best efforts the problem of embed coordination still exists in the construction industry.

*Corresponding author: Author email: dao0002@auburn.edu 
In the case of concrete construction if embeds are omitted or misplaced it will lead to costly rework because as the saying goes the "die has been cast." Post-setting concrete embeds after the concrete has been placed and cured is extremely disruptive to the construction process. In masonry construction some embeds need to be placed as the walls are laid and others are placed after the wall is constructed, in either case if the embeds are omitted or misplaced the rework involved is both costly and time consuming similar to concrete construction. The figures below illustrate some typical examples of embeds used in both concrete and masonry construction respectively.

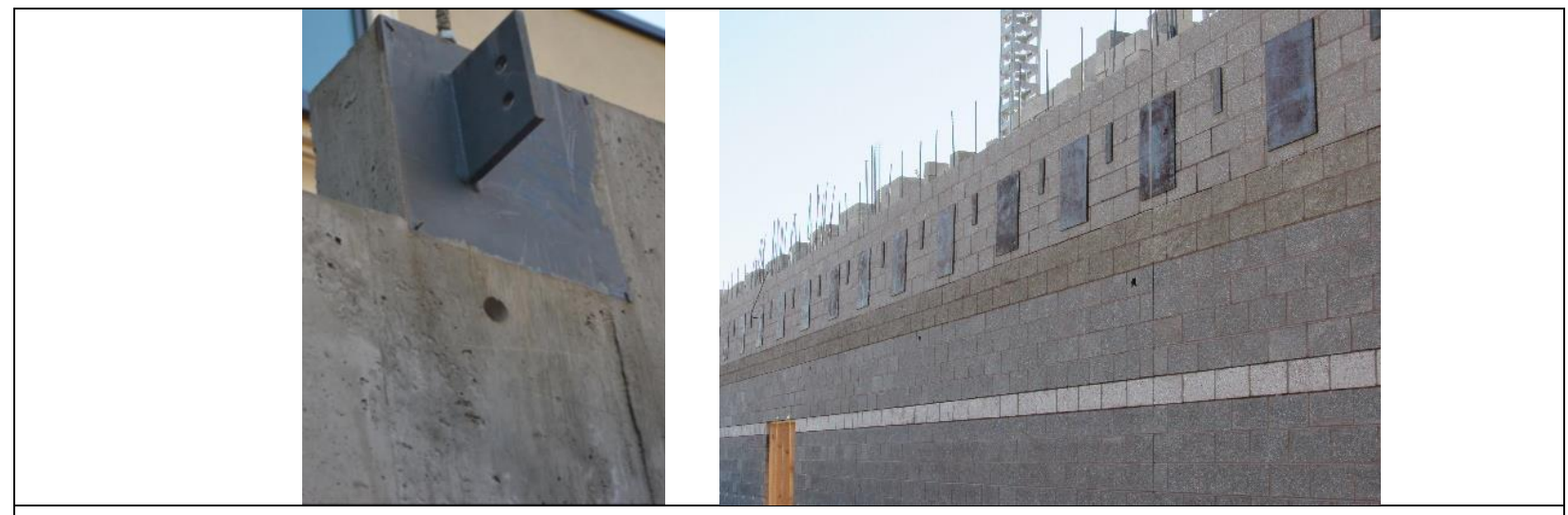

Figure 1. Embeds in concrete and masonry construction.

Traditionally embeds are located using "lift drawings" which are essentially drawings produced in the elevation or plan perspective which show the embed location in an $x-y$ plane. These drawings are typically produced by a member of the construction team who is tasked with coordinating the embed placement and inclusion. The embed locations are dimensioned in both the $\mathrm{x}$ and $\mathrm{y}$ plane on these two dimensional drawings. The process of producing these drawings and accurately placing the embeds is both time consuming and labour intensive.

Recently, representatives from our School met with members of our industry advisory council and they reiterated the need for a novel solution to this systemic problem. Our industry advisory council (IAC) is made up of construction industry leaders in the South-eastern portion of the United States, and part of their service to our school includes them bringing us current and relevant problems within the industry to use as research topics.

The representative from the industry advisory council who brought us this problem suggested we explore how Building Information Modelling (BIM) might provide some solutions. BIM is increasingly integrating traditional processes with more data-rich information that is streamlining the overall construction processes [1], therefore considering how BIM could be applied within a novel solution to this problem would be prudent. We took that recommendation one step further and wanted to explore not only how BIM might be used to resolve the problem but further how augmented reality combined with BIM could present a novel solution.

As opposed to virtual reality, augmented reality overlays the virtual world with the real world [2]. To do this augmented reality has to anchor a hologram to the real world environment via a series of sensors and devices through a process known as registration [3]. One of the most common augmented reality devices used in the market today is the Hololens made by Microsoft. The Hololens was selected as the augmented reality device for this study because we discovered that many industry partners in the school's IAC were using the same device in professional practice. Furthermore, in an industry-wide survey conducted by JB Knowledge in 2017 which included over 2,500 survey respondents, they reported that one of the most disruptive technologies that were "driving innovation" (p. 64) in the construction industry was augmented reality [4]. A fact that is repeated in their follow-up reports in 2018 and 2019 [5] [6]. 
Olsen, Kim \& Taylor / Proceedings of the Creative Construction Conference (2019) 125

https://doi.org/10.3311/CCC2019-125

Lastly, previous research has illustrated a favourable outcome in productivity and quality when augmented reality solutions were applied [8]. Therefore, it is imperative that solutions to the construction industry's anaemic productivity [7] be met with innovation and a platform that encourages the use of augmented reality.

\section{Methodology}

The goal of this research was to develop an experiment which would give us some early indications on whether augmented reality would be an effective piece of technology to utilize in resolving the problem of embed coordination. As stated above often times in construction embeds are omitted and misplaced leading to costly rework. The basic concept behind the experiment is that we would simulate embed verification on a construction site and utilize our construction management students as our test population to determine whether or not augmented reality allows for more efficient and accurate embed verification than traditional 2D "lift drawings."

For the experiment we decided to utilize and unfinished space within our department's building which has exposed masonry walls. The space itself was modelled using Revit and further to assure that the model was as close as possible to the actual construction a laser scan was used to match existing conditions. After the space was modelled we randomly placed steel embeds (Steel Plates, Angle Iron) within the model representative of what might be encountered on an actual construction site. See figure 2 below for an images of the model and the placement of the embeds.

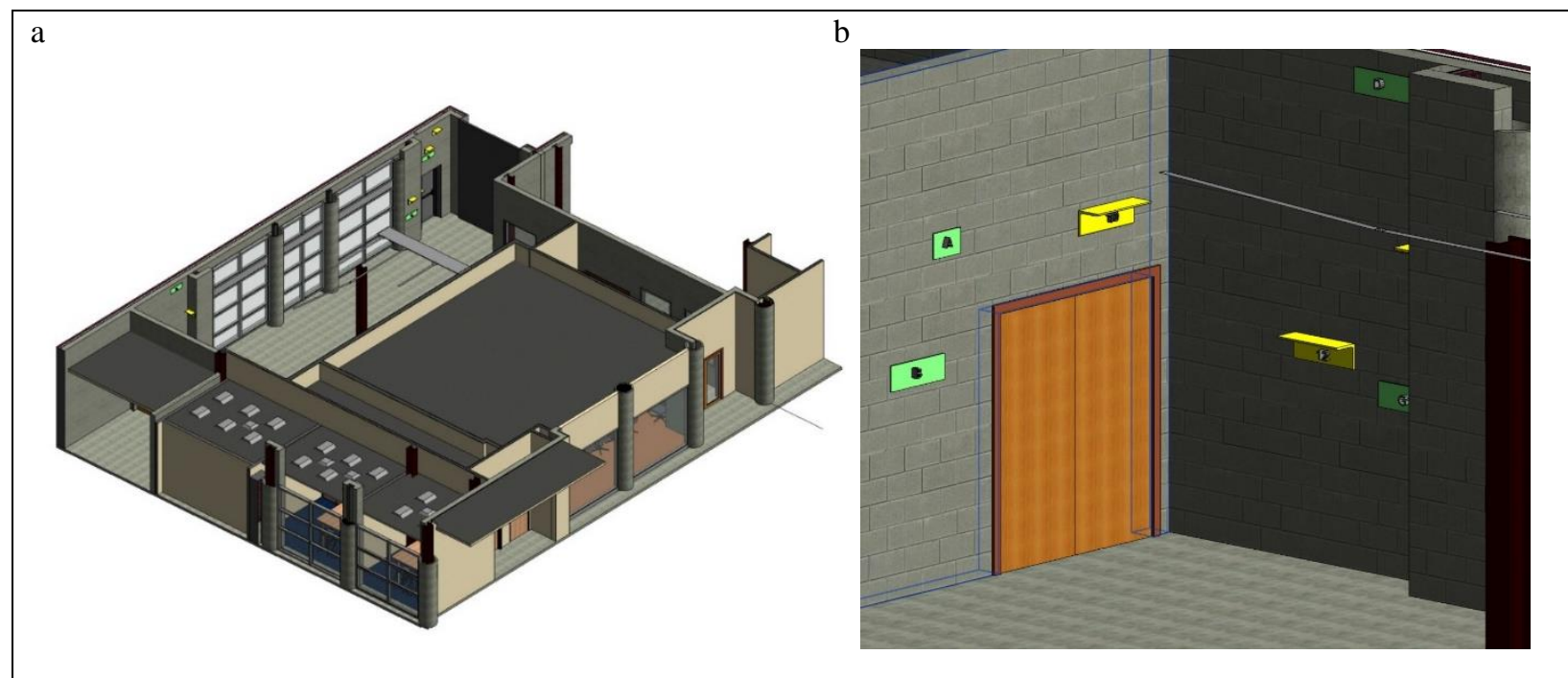

Fig. 2. (a) model of entire space (b) close-up of steel embeds

We exported this model to our augmented reality device (Hololens) using a relatively new app called "Hololive." This app allowed for direct export to the AR device from either Autodesk Revit or Navisworks. Also from this same model we produced 2D "lift drawings" as seen in the figure 3 below. 
Olsen, Kim \& Taylor / Proceedings of the Creative Construction Conference (2019) 125

https://doi.org/10.3311/CCC2019-125

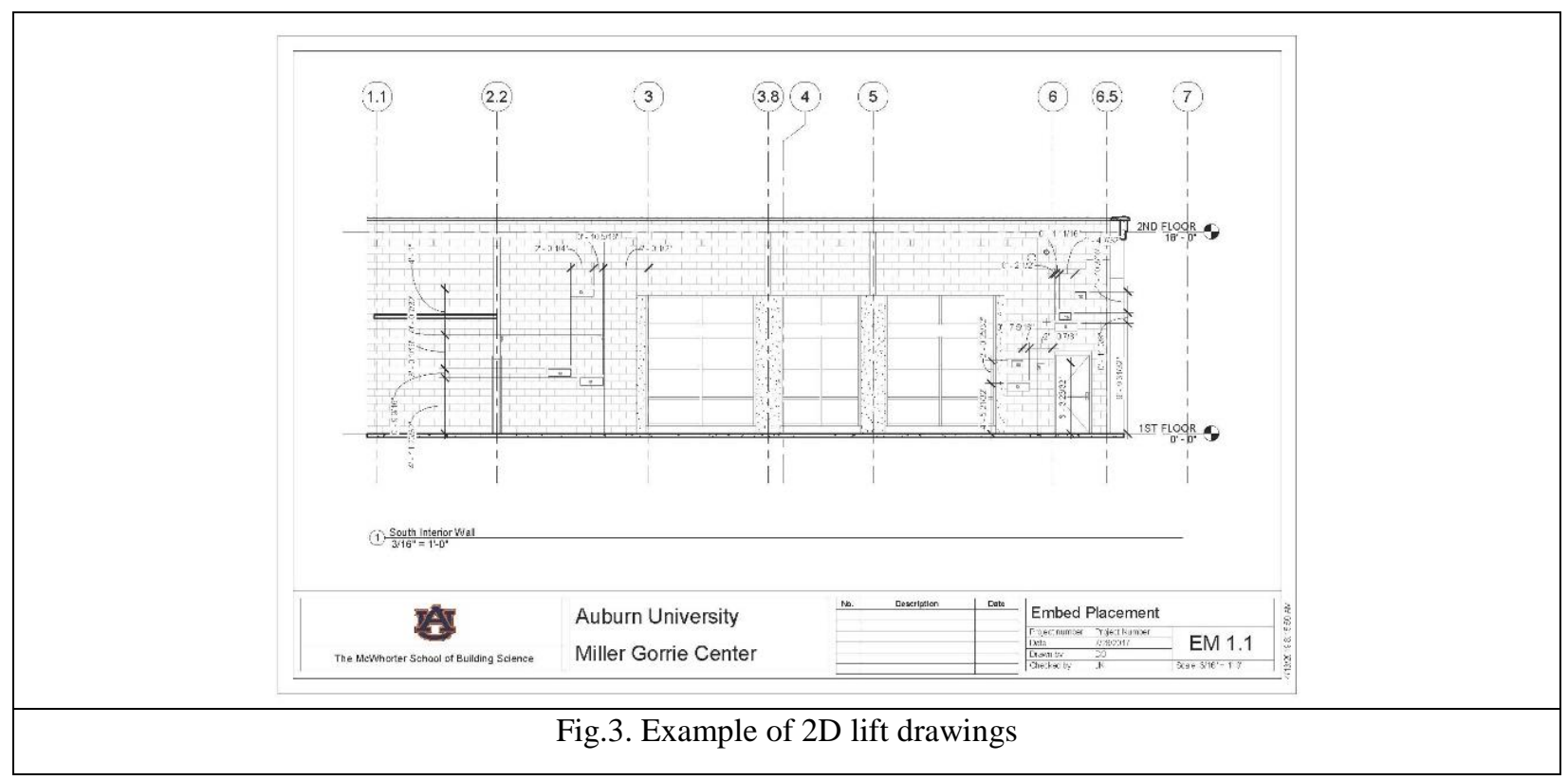

After the model was created templates were made of the steel embeds to hang on the wall. We mocked up the embeds with templates made of poster board. These templates were then precisely located with a Robotic Total Station. It was important to us to place the templates in their accurate positions so that we could investigate how drift and alignment issues might impact our ability to utilize the augmented reality device. See figures $4 \& 5$ below for pictures which show the layout of the templates and their placement within our experiment space.

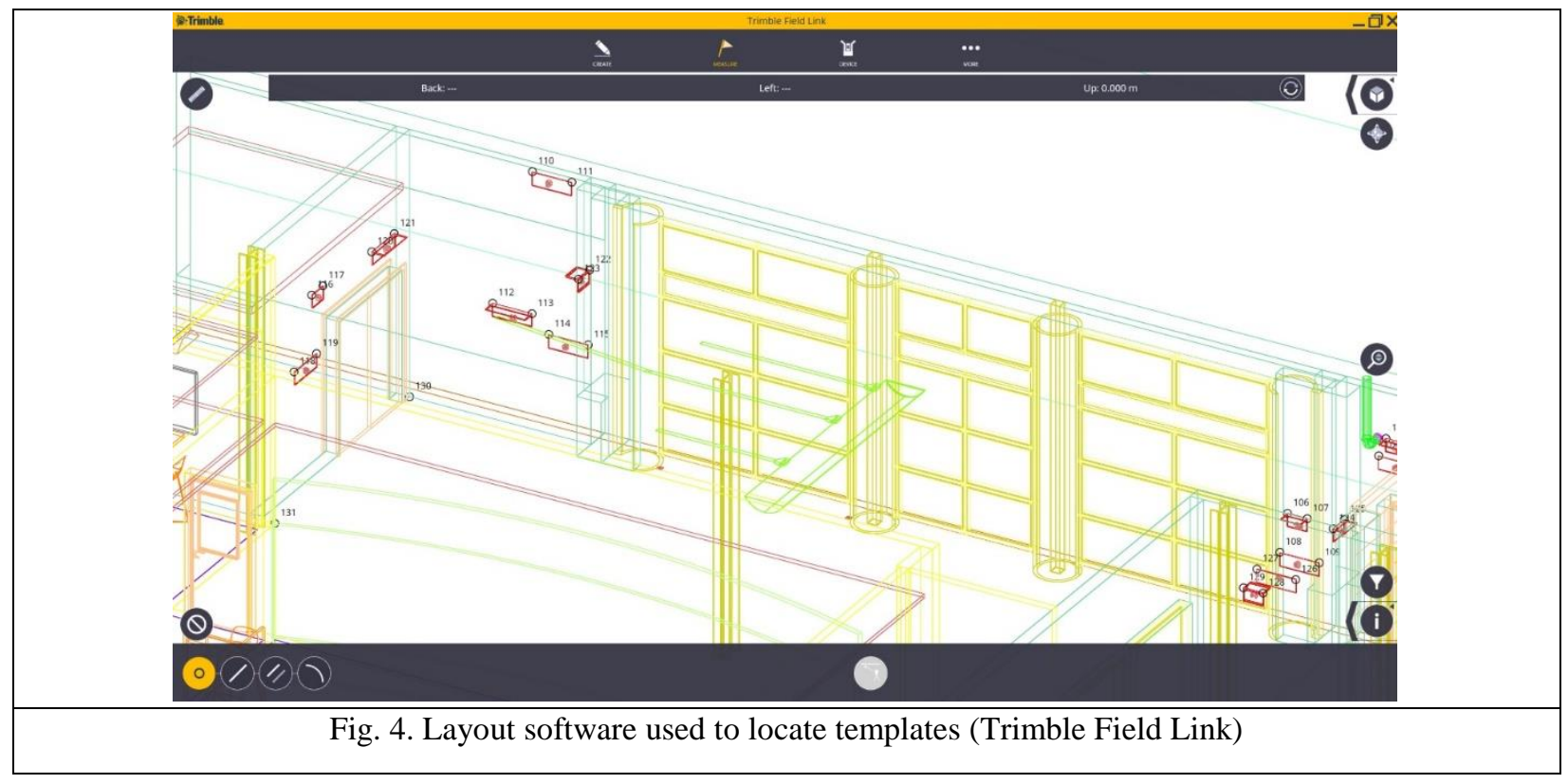




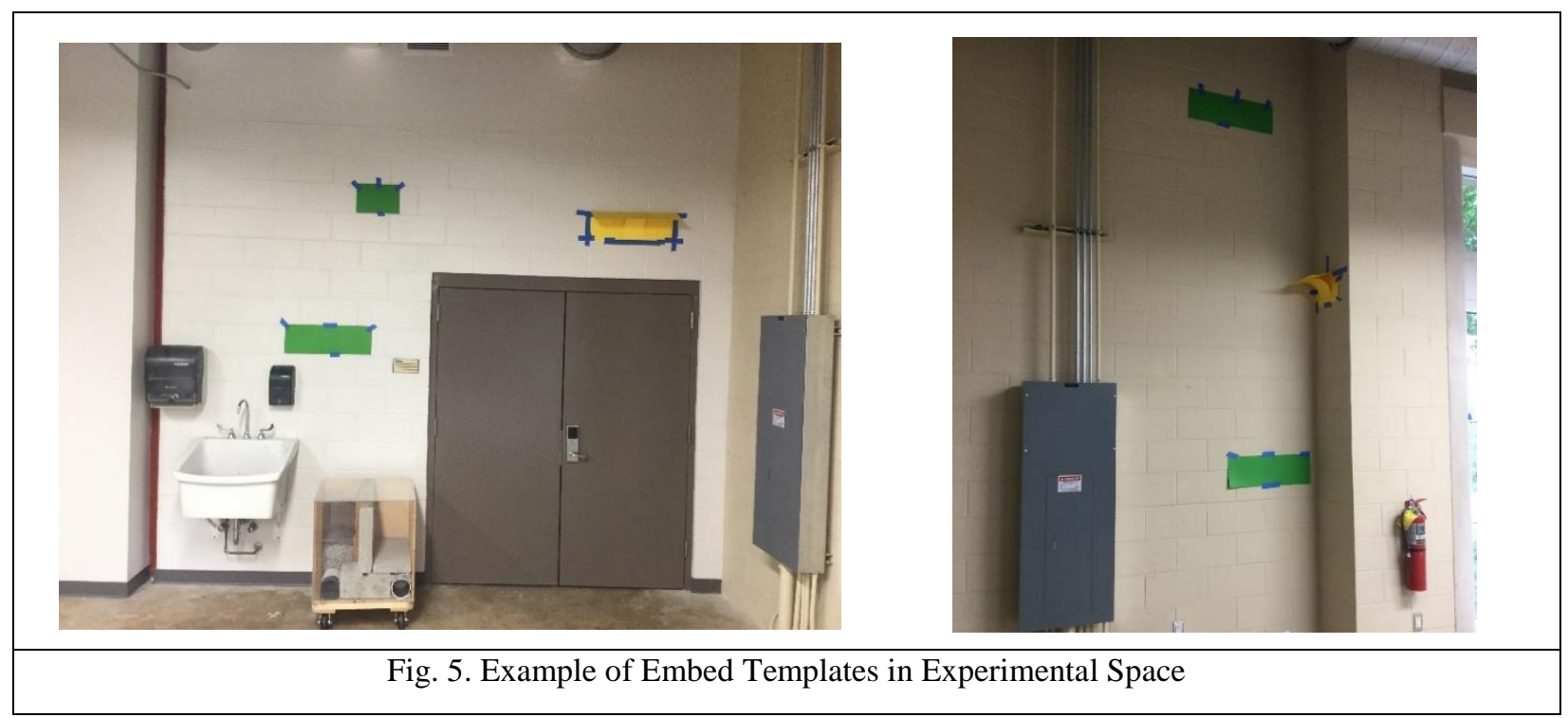

The test population consisted of 35 students some of whom went through the simulation with the lift drawings and some of whom went through the simulation with the Hololens and some of whom went through both exercises. Students were given approximately 6 minutes to complete their verification and inspections using both the 2D lift drawings and the Hololens. See figure 6 below images of the experiment process.

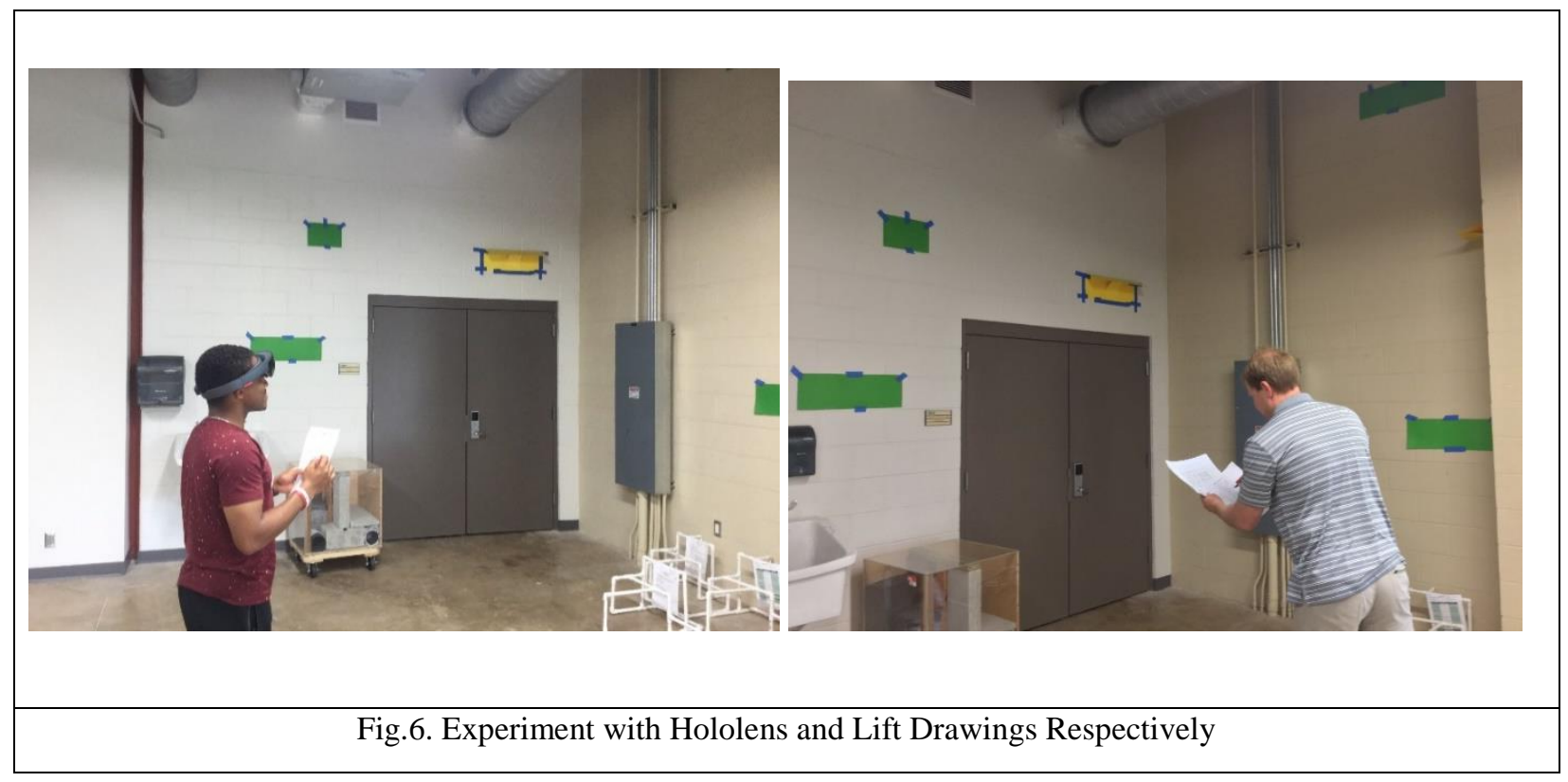

The hologram and the lift drawings contained 14 embeds which were supposed to be located and verified within a six minute time frame. Of the 14 embeds 3 were intentionally left out and not included, both the embeds that were included and those that were left out were to be spotted and verified by the test population. The same embed templates were used for both the hololens exercise and 2D lift drawing exercise. The results of this experiment are discussed and analysed below. 
Olsen, Kim \& Taylor / Proceedings of the Creative Construction Conference (2019) 125

https://doi.org/10.3311/CCC2019-125

\section{Results and Analysis}

Of the 35 students who participated in this experiment 11 completed both the "lift drawing" exercise and the "hololens" exercise, and the remaining 24 students completed one or the other of the two exercises. The 2D lift drawing exercise was done primarily to serve as a control for the Hololens exercise to derive if there is any benefit in utilizing the Hololens for embed coordination and verification.

We had a total of 25 students participate in the lift drawing exercise, during that exercise they were given approximately 6 minutes to either locate and verify all 14 embeds and identify which ones were missing. As was stated prior by design 3 of the embeds were missing and 11 of the embeds were installed. The results of the student's participation and the numbers of errors that were made are seen in the chart below.

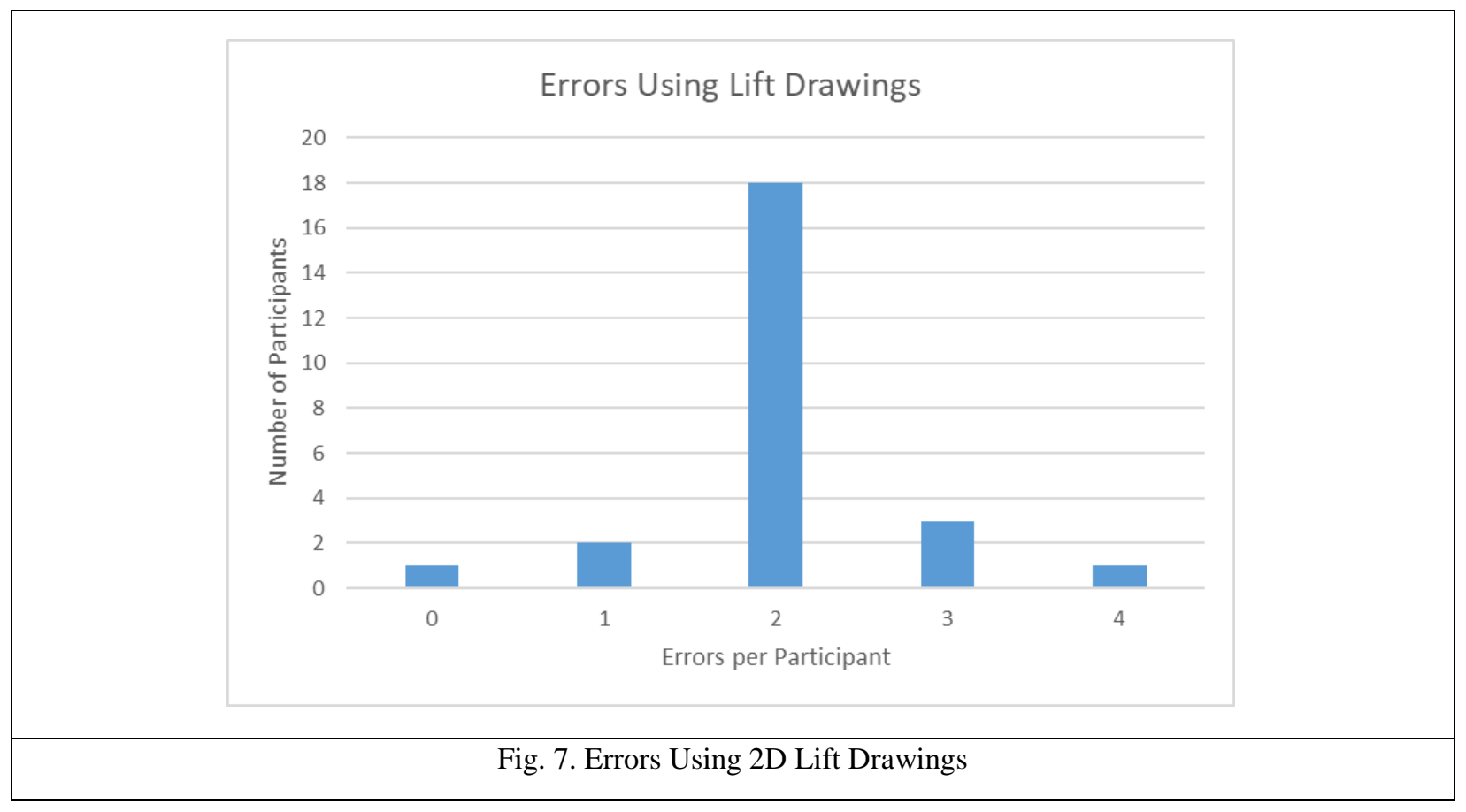

As seen above the median for number of embeds that were not properly verified was 2 and the mean was calculated at 2.04. There were generally two types of errors that a participant could make 1. Failing to Verify Completed Work 2. Failing to identify embeds that were never placed or omitted.

The embeds which were missed most frequently using the lift drawings were embeds numbers 15 and 21 . See the images of the model below in figure 9 which identifies those embeds. Their locations made it difficult for them to show up prominently on the "lift drawings." 

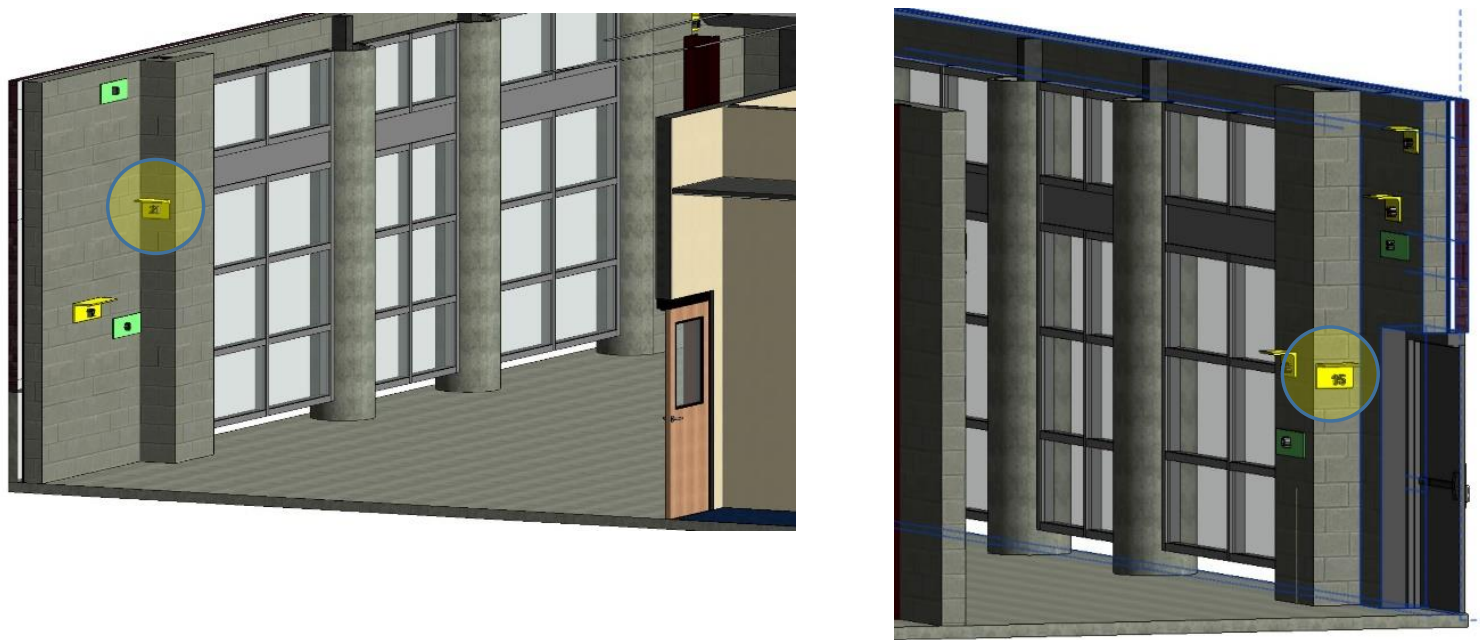

Fig. 9. Locations of Embeds which were most frequently missed with 2D lift drawings

We had a total of 21 students participate in the Hololens exercise, during that exercise they were given approximately 6 minutes to either verify or deny that all 14 embeds were either installed or missing. As was stated prior by design 3 of the embeds were missing and 11 of the embeds were installed. The results of the student's participation and the numbers of errors that were made are seen in figure 10 below.

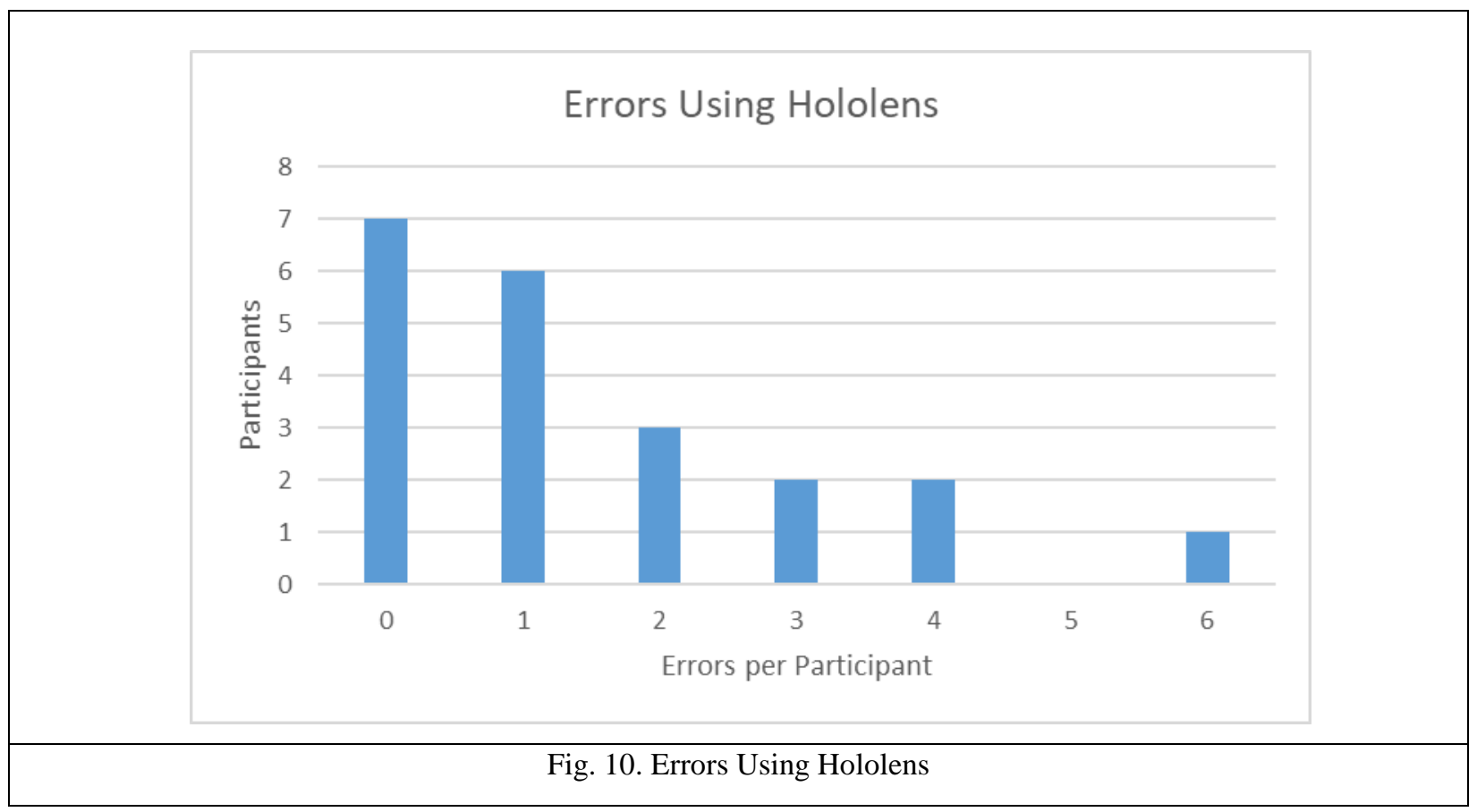

As seen above the median for number of embeds that were not properly verified was 1 and the mean was calculated at 1.52. There were generally two types of errors that a participant could make 1. Failing to Verify Completed Work 2. Failing to identify embeds that were never placed or omitted. 
Olsen, Kim \& Taylor / Proceedings of the Creative Construction Conference (2019) 125

https://doi.org/10.3311/CCC2019-125

\section{Conclusions}

During the course of this experiment it became clear that the Hololens showed promised for inspections and verification of concrete and masonry embedments. Although results appear to be somewhat preliminary we feel confident in the fact that the Hololens is an improvement over the "lift drawing' process in both time and precision. Time was not measured directly but it was a qualitative observation that the students who conducted the Hololens experiment finished significantly faster than those who participate in the 2D lift drawing control exercise. It also appeared that the Hololens allowed the students to better locate the embeds which would be traditionally hard to represent in 2D lift drawings. While drift and anchoring of the holograms were somewhat of an issue the technology was sufficient for accurate verification. While the technology was sufficient for verification and inspection it became clear that the technology still has some refinement to undergo before it is precise enough for installation and layout. After concluding this preliminary research on embed verification our data raised some new insights and questions that will be explored in future research.

\section{References}

[1] Eastman, C., Teicholz, P., Sacks, R., \& Liston, K. (2011). BIM Handbook: A Guide to Building Information Modeling for Owners, Managers, Designers, Engineers and Contractors. (L. Khelmani, Ed.), John Wiley \& Sons (2nd ed., Vol. 2). Wiley.

[2] Azuma, R. (1997). A survey of augmented reality. In Presence: Teleoperators and Virtual EnvironmentsPresence, 6(4), 355-385. https://doi.org/10.1162/pres.1997.6.4.355

[3] Webster, A., Feiner, S., MacIntyre, B., Massie, W., \& Krueger, T. (1996). Augmented reality in architectural construction, inspection and renovation. In Proc ASCE Third Congress on Computing in Civil Engineering (pp. 1-7). Retrieved from http://citeseerx.ist.psu.edu/viewdoc/download?doi=10.1.1.34.4415\&amp;rep=rep1\&amp;type=pdf

[4] JBKnowledge. (2017). The 6th Annual Construction Technology Report.

[5] JBKnowledge. (2018). The 7th Annual Construction Technology Report.

[6] JBKnowledge. (2019). The 8th Annual Construction Technology Report.

[7] Sveikauskas, L., Rowe, S., Mildenberger, J., Price, J., \& Young, A. (2016). Productivity Growth in Construction. Journal of Construction Engineering and Management, 142(10), 04016045. https://doi.org/10.1061/(ASCE)CO.1943-7862.0001138

[8] Segovia, D., Mendoza, M., Mendoza, E., \& Gonz??lez, E. (2015). Augmented Reality as a Tool for Production and Quality Monitoring. In Procedia Computer Science (Vol. 75). https://doi.org/10.1016/j.procs.2015.12.250 